\title{
Arrival and diversification of mabuyine skinks (Squamata: Scincidae) in the Neotropics based on a fossil-calibrated timetree
}

\author{
Anieli Guirro Pereira ${ }^{1}$, Carlos G Schrago ${ }^{\text {Corresp. } 1}$ \\ ${ }^{1}$ Department of Genetics, Universidade Federal do Rio de Janeiro, Rio de Janeiro, RJ, Brazil \\ Corresponding Author: Carlos G Schrago \\ Email address: carlos.schrago@gmail.com
}

Background: The evolution of South American Mabuyinae skinks holds significant biogeographic interest because its sister lineage is distributed across the African continent and adjacent islands. Moreover, at least one insular species, Trachylepis atlantica, has independently reached the New World through transoceanic dispersal. To clarify the evolutionary history of both Neotropical lineages, this study aimed to infer an updated timescale using the largest species and gene sampling dataset ever assembled for this group. By extending the analysis to the Scincidae family, we could employ fossil information to estimate mabuyinae divergence times and carried out a formal statistical biogeography analysis. To unveil macroevolutionary patterns, we also inferred diversification rates for this lineage and evaluated whether the colonization of South American continent significantly altered the mode of Mabuyinae evolution.

Methods: A time-calibrated phylogeny was inferred under the Bayesian framework employing fossil information. This timetree was used to (i) evaluate the historical biogeography of mabuiyines using the statistical approach implemented in BioGeoBEARS; (ii) estimate macroevolutionary diversification rates of the South American Mabuyinae lineages and the patterns of evolution of selected traits, namely, the mode of reproduction, body mass and snout-vent length; (iii) test the hypothesis of differential macroevolutionary patterns in South American lineages in BAMM and GeoSSE; and (iv) re-evaluate the ancestral state of the mode of reproduction of mabuyines.

Results: Our results corroborated the hypothesis that the occupation of the South American continent by Mabuyinae consisted of two independent dispersion events that occurred between the Oligocene and the Miocene. We found significant differences in speciation rates between the New World and the remaining Mabuyinae clades only in GeoSSE. The influence of phenotypic traits on diversification rates was not supported by any method. Ancestral state reconstruction suggested that the ancestor of South American mabuyine was likely viviparous.

Discussion: Our analyses further corroborated the existence of a transoceanic connection between Africa and South America in the Eocene/Oligocene period (Atlantogea). Following colonization of the isolated South America and subsequent dispersal through the continent by the ancestral mabuyine stock, we detected no difference in macroevolutionary regimes of New World clades. This finding argued against the ecological opportunity model as an explanation for the diversity of living mabuyines. 
1 Arrival and diversification of mabuyine skinks (Squamata: Scincidae) in the Neotropics

2 based on a fossil-calibrated timetree

3

4 Anieli G. Pereira and Carlos G. Schrago*

5 Department of Genetics, Federal University of Rio de Janeiro, RJ, Brazil

6

7

8

9

10

*Corresponding author:

11 Instituto de Biologia, Departamento de Genética, CCS, A2-092

12 Rua Prof. Rodolpho Paulo Rocco, SN

13 Cidade Universitária

14 Rio de Janeiro, RJ

15 CEP: 21941-617

16 BRAZIL

17 Phone: +55 21 2562-6397

18 Phone: +55 21 4063-8278

19 Email: carlos.schrago@gmail.com 
20 Abstract

21

22 Background: The evolution of South American Mabuyinae skinks holds significant

23 biogeographic interest because its sister lineage is distributed across the African continent and

24 adjacent islands. Moreover, at least one insular species, Trachylepis atlantica, has independently

25 reached the New World through transoceanic dispersal. To clarify the evolutionary history of

26 both Neotropical lineages, this study aimed to infer an updated timescale using the largest

27 species and gene sampling dataset ever assembled for this group. By extending the analysis to

28 the Scincidae family, we could employ fossil information to estimate mabuyinae divergence

29 times and carried out a formal statistical biogeography analysis. To unveil macroevolutionary

30 patterns, we also inferred diversification rates for this lineage and evaluated whether the

31 colonization of South American continent significantly altered the mode of Mabuyinae

32 evolution.

33 Methods: A time-calibrated phylogeny was inferred under the Bayesian framework employing

34 fossil information. This timetree was used to (i) evaluate the historical biogeography of

35 mabuiyines using the statistical approach implemented in BioGeoBEARS; (ii) estimate

36 macroevolutionary diversification rates of the South American Mabuyinae lineages and the

37 patterns of evolution of selected traits, namely, the mode of reproduction, body mass and snout-

38 vent length; (iii) test the hypothesis of differential macroevolutionary patterns in South American

39 lineages in BAMM and GeoSSE; and (iv) re-evaluate the ancestral state of the mode of

40 reproduction of mabuyines.

41 Results: Our results corroborated the hypothesis that the occupation of the South American

42 continent by Mabuyinae consisted of two independent dispersion events that occurred between

43 the Oligocene and the Miocene. We found significant differences in speciation rates between the

44 New World and the remaining Mabuyinae clades only in GeoSSE. The influence of phenotypic

45 traits on diversification rates was not supported by any method. Ancestral state reconstruction

46 suggested that the ancestor of South American mabuyine was likely viviparous.

47 Discussion: Our analyses further corroborated the existence of a transoceanic connection

48 between Africa and South America in the Eocene/Oligocene period (Atlantogea). Following

49 colonization of the isolated South America and subsequent dispersal through the continent by the

50 ancestral mabuyine stock, we detected no difference in macroevolutionary regimes of New 
51 World clades. This finding argued against the ecological opportunity model as an explanation for 52 the diversity of living mabuyines. 


\section{Introduction}

54

The subfamily Mabuyinae comprises 24 genera and 197 species of lizards and belongs to

the highly diverse worldwide family, Scincidae (Lepidosauria; Squamata) (Uetz and Hosek,

2015). The Mabuyinae, as well as the Scincidae, are distributed on nearly all continents.

Approximately one-third of the species in this subfamily are from the Neotropical region, and they are the only representatives of scincids in South America.

The entire diversity of mabuyine species was traditionally assigned to the single genus,

61

62

63

64

65

66

67

68

69

70

71

72

Mabuya, but a previous analysis proposed four new monophyletic genera with well-defined geographical distributions (Mausfeld et al., 2002): (1) Trachylepis (previously Euprepis), comprising African and Madagascan species with one South American representative ( $T$. atlantica); (2) Eutropis, containing Asian species; (3) Chioninia, from the Cape Verde islands; and (4) Mabuya, containing New World species, recently rearranged into 16 new genera by Hedges and Conn (2012). Hedges and Conn (2012) treated South American Mabuyinae as a clade of family Mabuyidae, within the superfamily Lygosomoidea. The new Mabuyidae consisted of four new subfamilies: Mabuyinae, Chioniniinae, Dasiinae and Trachylepidinae. Hedges and Conn's arrangement disregarded many genera previously related to Mabuyinae, such as Eutropis, Lankaskincus, and Ristella (Pyron et al., 2013), and recent papers have questioned this classification (e.g. Pyron et al., 2013, Pinto et al., 2015, Karin et al., 2016). Recently, alternative classifications were suggested. For instance, Karin et al. (2016) placed the MiddleEastern Trachylepis (T. aurata, T. vittatus, and T. septemtaeniatus) into the genus Heremites and Eutropis novemcarinata into Toenayar novemcarinata. Moreover, Pinto et al. (2015) assigned species from the genera Maracaiba and Alinea back to genus Mabuya and Metallinou et al. 
76 (2016) reclassified Trachylepis ivensii as Lubuya ivensii. In this study, we followed the Reptile

77 Database (Uetz and Hosek, 2015) taxonomy as of January 2017, which classified this clade as

78 subfamily Mabuyinae of the family Scincidae.

79 Therefore, at least two phylogenetically distinct lineages of Mabuyinae are distributed in

80 the New World, namely, T. atlantica and the Continental American Mabuyinae (CAM) clade.

81 These lineages are distinguished by both morphological features - presacral vertebrae counts,

82 keeled dorsal scales, coloration, and oviparity (Greer, 1970) - and molecular evidence (e.g.

83 Mausfeld and Vrcibradic, 2002; Carranza and Arnold, 2003; Whiting et al., 2006). It is

84 customary to assume that the history of Mabuyinae in South American continent consisted of

85 two independent transoceanic dispersal events from the Old World (Mausfeld and Vrcibradic,

86 2002; Carranza and Arnold, 2003; Whiting et al., 2006). The spatial distribution of the single

87 representative of the genus Trachylepis in an island closer to South America than to Africa, $T$.

88 atlantica, is of particular interest. This issue is so intriguing that it has reached the pages of

89 nontechnical literature (de Queiroz, 2014). T. atlantica is found in Fernando de Noronha, a small

90 volcanic archipelago in the Atlantic Ocean that lies $375 \mathrm{~km}$ from the northeastern coast of Brazil

91 and that was geologically formed from the Miocene (12.3 Ma) to the upper Pliocene, from $3.3-$

92 1.7 Ma (Almeida, 2002). Although other Trachylepis species have spread to several islands near

93 the African continent, the presence of T. atlantica in Fernando de Noronha likely represents the

94 farthest dispersal registered for the genus.

95 The CAM lineage, on the other hand, contains approximately 60 species of Mabuyinae.

96 Previous studies have suggested that the split between this clade and the African Mabuyinae

97 (genus Trachylepis) occurred from 28 - 34 Ma (Hedges and Conn, 2012; Karin et al., 2016).

98 Additionally, the age of the last common ancestor (LCA) of the CAM was dated at $7-9 \mathrm{Ma}$ 
99 (Carranza and Arnold, 2003; Pinto-Sanchez et al., 2015) and 11 - 14 Ma (Miralles and Carranza,

100 2010; Hedges and Conn, 2012; Karin et al., 2016). Considering the present-day Atlantic Ocean

101 currents, Mausfeld et al. (2002) suggested that $T$. atlantica could have dispersed from the coast

102 of Southwest Africa to South America, but no work to date has comprehensively evaluated this

103 hypothesis. The older estimated ages could be consistent with the supposed faunal transoceanic

104 connection between Africa and South America during the Eocene/Oligocene (e.g. hystricognath

105 rodents, Loss-Oliveira et al., 2012; Voloch et al., 2013; anthropoid primates, Schrago et al.,

106 2012; 2013; amphisbaenians, Vidal et al., 2008; emballonurid bats, Teeling, 2005; Leigh et al.,

107 2013; testudinid turtles, Le et al., 2006) through a single or a series of islands constituting an

108 Atlantic Ocean Ridge (the Atlantogea paleo province) (Simpson, 1950; Poux et al., 2006; de

109 Oliveira et al., 2009; Ezcurra and Agnolin, 2012; de Queiroz, 2014). This transatlantic island

110 corridor, associated with a drop in the sea level in the Oligocene, could explain faunal exchanges

111 in this period (de Queiroz, 2014). Regarding T. atlantica, there is a lack of estimates of the age of

112 the separation between this species and its African sister lineage.

113 Chronological information is indispensable for a full understanding of the scenario

114 underlying the current geographic distribution and evolutionary history of extant lineages

115 (Sanmartín et al. 2008; Loss-Oliveira et al. 2012). However, estimates of divergence times

116 within the Mabuyinae have been hampered by the lack of fossils for Mabuyinae, which made

117 previous researchers rely on evolutionary rates borrowed from the literature (e.g., Carranza and

118 Arnold, 2003; Miralles and Carranza, 2010; Lima et al., 2013; Barker et al., 2015; Karin et al.,

119 2016) or to employ biogeographic events as calibrations (Hedges and Conn, 2012; Pinto-Sanchez

120 et al., 2015) to derive the timescale of this lineage. The fossil record, however, has been

121 demonstrated to be much more informative than biogeographic events as a calibration tool 
122 (Heads, 2011). The use of biogeographic events to time-calibrate phylogenies requires the

123 assumption of vicariant scenarios of diversification, which entails that the speciation is

124 synchronous with the breaking apart of landmasses, or that island colonization occurs

125 immediately following geological formation (Heads, 2011; Mello and Schrago, 2012).

126 Revealing the origin and diversification of the CAM clade and T. atlantica also requires a

127 robust phylogenetic hypothesis. Although it is generally accepted that $T$. atlantica is a member of

128 the genus Trachylepis and therefore excluded from the main diversification of the CAM, its

129 evolutionary affinity remains controversial (Mausfeld et al., 2002; Carranza and Arnold, 2003;

130 Whiting et al., 2006). Early proposed phylogenies of Mabuyinae used a maximum of 35 species,

131 a number that significantly underrepresents the diversity of this subfamily (Mausfeld et al., 2002;

132 Carranza and Arnold, 2003; Whiting et al., 2006). Hedges and Conn (2012) studied the CAM

133 clade exclusively and included 40 species, whereas the large-scale Squamata phylogeny of Pyron

134 et al. (2013), which contains 4,161 species, sampled 71 mabuyine skink species. Recently, Pinto

135 Sanchez et al. (2015) used 250 specimens to infer the phylogeny and species diversity of

136 neotropical mabuyinaes, focusing on Colombian populations. Karin et al. (2016) analyzed the

137 higher-order relationships of Mabuyinae using 22 species ( 24 specimens). Considering that

138 improvements in phylogenetic inference and divergence time estimation can be obtained by

139 increasing taxon sampling (Linder et al., 2005; Albert et al., 2009; Soares and Schrago, 2012),

140 this matter requires further investigation.

141 Moreover, the occupation of the South American mainland by the CAM motivates an

142 analysis of differential rates of diversification and rates of phenotypic traits evolution in this

143 clade. It has been broadly reported that the ecological opportunity of a new environment can

144 induce acceleration of macroevolutionary rates (Yoder et al., 2010; Liedtke et al., 2016). This 
145 phenomenon was documented for insular vertebrates (Losos JB, Mahler DL. 2010; Jonsson KA

146 et al. 2012); but, as proposed by G.G. Simpson (1953), the occupation of a new continent also

147 could trigger evolutionary radiations (Yoder JB et al. 2010; Pires MM, Silvestro D, Quental TB.

148 2015).

149 In this study, as a means of exploring the continental biogeographic and evolutionary

150 patterns associated with the occupation of South America by mabuyine skinks, we estimated the

151 molecular phylogeny and inferred the divergence times of its members employing fossil

152 information. The inferred time-tree was used to perform, for the first time, a formal statistical

153 analysis of the historical biogeography and macroevolutionary diversification rates of

154 Mabuyinae. To this end, by combining previously published data, we assembled the largest

155 dataset of species and gene sampling composed to date, with the aim of uncovering the evolution 156 of the Mabuyinae. 


\section{Materials and Methods}

159

160

161

162

163

164

165

166

167

168

169

170

171

172

173

174

175

176

177

178

179

180

Data collection, alignment, and taxonomy

We assembled a chimeric supermatrix from previously published sequence data available in GenBank. A total of eight genetic loci from 117 species of Mabuyinae, as well as 103

additional Scincid genera were analyzed, summing 220 taxa, with two genera of the family

Xantusiidae used as outgroups. All seven genes available from Trachylepis atlantica were used in our analysis: the mitochondrial ribosomal genes $12 S \operatorname{rRNA}, 16 \mathrm{~S} r R N A$ and the coding gene cytochrome b (cytb); as well as the nuclear genes alpha enolase (enol), oocyte maturation factor (cmos), glyceraldehyde-3-phosphate dehydrogenase (gapdh), myosin heavy chain (myh), and G protein-coupled receptor 149 (gpr149). The accession numbers are available in Supplementary File 1. When several sequences representative of each taxon were available, the longest sequence was selected. In order to simultaneously decrease the number of missing data and to increase the number of representative taxa, we assumed genera and species as monophyletic. Therefore, chimeric supermatrices were used. All protein-coding sequences were visually checked for stop codons and aligned individually in SeaView v. 4.4.3 (Gouy et al., 2010) using the MUSCLE v. 3.8.31 (Edgar 2004) algorithm, whereas the ribosomal genes were aligned in MAFFT v. 7 (Katoh and Standley, 2013). Gblocks v. 0.91b (Castresana, 2000; Talavera and Castresana, 2007) was used to exclude poorly aligned bases and divergent regions in the $12 S r R N A, 16 S r R N A$, and enol genes. Individual genes were then concatenated into a single supermatrix using the $\mathrm{R}$ package Phyloch (Heibl, 2015). RogueNarok (Aberer et al., 2013) was used to identify taxa without significant phylogenetic information using a ML tree and associated bootstrapped topologies.

These datasets were inferred under a rapid bootstrapping algorithm analysis with 200 replicates 
181 (Stamatakis et al., 2008), followed by a thorough search of the ML tree using the evolutionary

182 model GTRGAMMA, performed in RAxML-HPC (8.1.24) (Stamatakis, 2014). Based on the

183 relative bipartition information criterion (RBIC) inferred by RogueNarok, the terminal nodes

184 Larutia and Otosaurus (RBIC > 1.0), were removed from the analysis. Another dataset,

185 assembled with a more stringent $(\mathrm{RBIC}>0.5)$ criterion, was composed for comparison. Under

186 this criterion, the genus Lankascincus and the mabuyine species Eumecia anchietae and

187 Trachylepis acutilabris were excluded from the analyses. The results, however, were robust for

188 both RBIC values, and we report the results under RBIC $>1.0$ hereafter. The final supermatrix

189 consisting of 4,131 base pairs are available in Supplementary File 2, and detailed information on

190 each locus of the final alignment was listed in Table 1.

191

192 Evolutionary analyses

193 We investigated 18 candidate partitioning schemes using PartitionFinder heuristic search

194 algorithm with the Bayesian information criterion (BIC) for model selection (Lanfear et al.,

195 2012). The partitioning schemes also tested codon positions of protein-coding genes. The

196 partitioning strategy with the best fit consisted of 7 partitions (Supplementary File 3), which

197 were used throughout the analyses. Maximum likelihood (ML) phylogenetic inference was

198 performed in RAxML-HPC (8.1.24) employing the evolutionary model GTRCAT. The GTR

199 substitution model was applied to each partition, as this is the only model supported in RAxML.

200 ML analyses used 200 initial searches for finding the optimal tree topology. Statistical support

201 for clades was assessed using 2,000 standard nonparametric bootstrap replicates (PB).

202 Inference of node ages was performed with the mcmctree program of the PAML 4.8a

203 package (Yang, 2007). For large alignments, the Bayesian inference of node ages via Markov 
204 chain Monte Carlo is computationally intensive. To make the analyses feasible, we used an 205 approximate likelihood calculation modified from Thorne et al. (1998) and implemented in 206 mcmctree (Reis and Yang, 2011). Priors for the rgene and sigma2 parameters were set as $G(2$, $207200)$ and $G(1,10)$, respectively. Markov chains were sampled every 1,000 generations until 20850,000 trees were collected. The analysis was performed twice to check for convergence of the 209 chains. Effective sample sizes (ESS) of parameters were calculated in Tracer v. 1.5, and all 210 values were greater than 200 .

\section{Calibration priors}

213 The age of the root, which corresponds to the split between the families Scincidae and 214 Xantusiidae, was calibrated at a minimum value of $70.6 \mathrm{Ma}$ and a maximum age of 209.5 Ma.

215 The minimum was set according to the oldest scincid from the Late Cretaceous of North 216 America (Campanian, 83.5 - 70.6 Ma), as previously adopted by Mulcahy et al. (2012) (Rowe et 217 al., 1992); while the maximum was set according to Benton et al. (2015), which proposed a 218 maximum age of the ancestral of Squamata. Additional calibration information was gathered

219 from the PaleoBioDB (paleobiodb.org) and entered as minimum ages of the stem nodes of 220 clades. The minimum age of the Scincidae stem node was calibrated at $20.4 \mathrm{Ma}$, based on the

221 oldest crown scincid Eumeces antiquus classified as a member of the subfamily Scincinae 222 (Holman, 1981; Estes, 1983). The stem node of the clade containing the extant genus Eumeces 223 was calibrated at a minimum age of 13.6 Ma based on fossils from the Middle Miocene in North 224 America (Holman, 1966; Voorhies et al., 1987; Joeckel, 1988). The age of an extinct Egernia sp.

225 from the Miocene of Hungary ( $>5 \mathrm{Ma}$ ) was used to calibrate the stem node of the clade 226 containing this extant genus (Venczel and Hír, 2013). According to Böhme (2010), the fossil 
227 Tropidophorus bavaricus belongs to extant genus Tropidophorus, and it was used to calibrate the

228 stem node of this clade, setting its minimum age at 13.6 Ma (Böttcher et al., 2009). Calibration

229 nodes are shown in the Supplementary Figure 4.

230

231

Ancestral area reconstruction

232 A historical biogeographical reconstruction was performed for the subfamily Mabuyinae and its

233 sister clade (Lankascincus and Ristella). The R package BioGeoBEARS (Matzke 2013) was used

234 to run likelihood methods: DIVALIKE (a likelihood interpretation of DIVA that allows for the

235 same events as DIVA - Matzke, 2013) and DEC (Dispersal-Extinction-Cladogenesis, Ree and

236 Smith, 2008). In BioGeoBEARS, we used the likelihood ratio to test whether the null models

237 (DIVALIKE and DEC) fitted the data better than did the more sophisticated models

238 (DIVALIKE+J and DEC+J). The "J" in models represents the addition of the founder-event

239 speciation, thereby allowing dispersal without range expansion (Matzke 2014). The maximum

240 range size, which limits the number of areas defined by tips and nodes, was set to two, based on

241 the current geographic distribution of species. Constraints on dispersal or area availability were

242 not included. To make the biogeographic analysis computationally feasible, islands were not

243 considered independent regions. The rationale for choosing the seven biogeographic areas

244 follows the zoogeographical regions found in the herpetological and biogeographical literature

245 (Vitt and Caldwell, 2009; Lomolino, 2010; Morrone, 2014; Pyron, 2014): (1) Neotropical

246 Brazilian Subregion (B), (2) Neotropical Chacoan Subregion (C), (3) West Indies - Caribbean

247 Islands (W); (4) Oriental Region (O): Southeast Asia + Philippines + Indian Subcontinent

248 (Pakistan to Bangladesh, including Sri Lanka, Nepal, and Bhutan); (5) Afrotropical (A): Sub-

249 Saharan Africa; (6) Madagascar (M): Madagascar and adjacent islands (the Seychelles and the 
250 Comoros); and (7) Saharo-Arabian (S): Europe + North Africa + the northern portion of the

251 Arabian Peninsula + Southwest Asia. Using online distributional data from the Reptile Database

252 (Uetz and Hosek, 2015), we classified the tips as belonging to one or more of these areas.

253

254 Rate of species diversification and diversification-phenotype rate correlation

255 Our dated phylogeny of Mabuyinae was used to infer the dynamics of species

256 diversification using BAMM 2.5 (Bayesian Analysis of Macroevolutionary Mixtures - Rabosky,

257 2014), which simultaneously accounts for variation in evolutionary rates through time and

258 among lineages using transdimensional (reversible-jump) Markov chain Monte Carlo (rjMCMC)

259 (Rabosky 2014). Markov chains were sampled every $1,000^{\text {th }}$ generation until 37,500 trees were

260 collected after a burn-in of $25 \%$. Prior distributions were set according to setBAMMPriors

261 function from the BAMMtools R package (Rabosky et al. 2014). The frequencies of the species

262 in each genus were considered.

263 We also tested for trait-dependent diversification. The following traits were collated from the

264 literature: (i) data on the reproductive mode for 60 species of the Mabuyinae - 39 species as

265 viviparous, 17 as oviparous, and 3 as ovoviviparous (Meiri et al. 2013; Pyron and Burbrink

266 2013); (ii) the SVL (snout-vent length) for 46 species (Meiri 2010; Miralles and Carranza, 2010;

267 Das 2010; Hedges and Conn, 2012; Meiri et al. 2013; Pyron and Burbrink 2013); and (iii) the

268 body mass data for 35 species (Meiri 2010; Hedges and Conn, 2012). Following previous works,

269 we treated "ovoviviparity" as viviparity (Pyron and Burbrink 2013).

270 Differences in the rates of speciation $(\lambda)$ and extinction $(\mu)$ between New World $(N W)$

271 and Old World $(\overline{N W})$ areas and between viviparous $(V)$ and non-viviparous $(\bar{V})$ lineages were

272 tested using two approaches. Firstly, an ANOVA, implemented in the R package diversitree 
273 (FitzJohn 2012), was used to compare different macroevolutionary regimes. In the $N W / \overline{N W}$

274 comparison, rates were calculated using the GeoSSE approach (Goldberg et al. 2011), whereas

275 BiSSE was used to test $V / \bar{V}$ rates, with both tests of binary characters as implemented in

276 diversitree. In this sense, GeoSSE first optimised the parameters under an unconstrained full

277 model, in which ML estimates were obtained for (i) the speciation rate of the New World lineage

$278\left(\lambda_{N W}\right)$; (ii) the speciation rate of non-New World lineages $\left(\lambda_{\overline{N W}}\right)$; (iii) the extinction rate of the

279 New World clade $\left(\mu_{N W}\right)$; (iv) the extinction rate of non-New World lineages $\left(\mu_{\overline{N W}}\right)$; (v) the

280 intermediate speciation rate parameter $\left(\lambda_{N W, \overline{N W}}\right) ;($ vi) the dispersal rates from the New World

281 clade $\left(d_{N W \rightarrow \overline{N W}}\right)$; and (vii) the dispersal rates of the sister lineages $\left(d_{\overline{N W} \rightarrow N W}\right)$. Similarly, BiSSE

282 was used to infer (i) the speciation rate of the viviparous lineage $\left(\lambda_{V}\right)$; (ii) the speciation rate of

283 non-viviparous lineages $\left(\lambda_{\bar{V}}\right)$; (iii) the extinction rate of the viviparous clade $\left(\mu_{V}\right)$; (iv) the

284 extinction rate of non-viviparous lineages $\left(\mu_{\bar{V}}\right) ;(\mathrm{v})$ transition rates from the viviparous clade (

$\left.285 q_{V \rightarrow \bar{V}}\right)$; and (vi) transition rates of the sister clade $\left(q_{\bar{V} \rightarrow V}\right)$. Initial parametric values were set

286 according to the starting.point function from the diversitree package with an initial ratio of 0.5.

287 This preliminary step was required to build the likelihood function (the make command). In

288 BiSSE, species with unknown states were coded as 'NA' and assigned the sampling fraction of

289 the species of Mabuyinae used in this work ( $\sim 61 \%)$, independent of the character state.

290 Subsequently, to perform the ANOVA test of the GeoSSE results, we chose to constrain the

291 intermediate speciation and the dispersal rate parameters to zero $\left(\lambda_{N W, \overline{N W}}=d_{N W \rightarrow \overline{N W}}=\right.$

$292 d_{\overline{N W} \rightarrow N W}=0$ ), in order to compare speciation and the extinction rates within regions exclusively.

293 Finally, we tested macroevolutionary alternative models against the full models (Table 2).

294 The second comparison between $N W / \overline{N W}$ and $V / \bar{V}$ macroevolutionary regimes used the 
295 marginal posterior distributions of macroevolutionary parameters, inspected using the R package 296 diversitree. These distributions were obtained using the MCMC analyses, with samples taken in

297 diversitree every $1,000^{\text {th }}$ generation until 1,000 samples were collected. A broad exponential 298 prior (mean of 0.5 ) for all parameters was used, as recommended, while the $\lambda$ and $\mu$ rates were 299 set as the values obtained in the ML full model (FitzJohn 2012). For the $N W / \overline{N W}$ relationship, 300 we also used the marginal posterior distributions obtained from BAMM, applying the 301 getCladeRates function of the BAMMtools R package. For all approaches, we calculated the $30295 \%$ highest posterior density (HPD) interval for the difference between the means of the $N W /$ $303 \overline{N W}$ and $V / \bar{V}$ lineages (Bolstad 2007). The diversification-phenotype rate correlation was performed in STRAPP (Rabosky and 305 Huang 2015), as implemented in BAMMtools. To run STRAPP, phylogenies were pruned to 306 match the available information for both tree terminals and traits. Diversification analysis results

307 previously obtained using BAMM were pruned to match the available trait information using the 308 function subtreeBAMM and were tested against the analyzed traits, using the Mann-Whitney 309 method for binary characters and both Pearson and Spearman methods for continuous traits.

\section{Rate of trait evolution and ancestral state reconstruction}

We inferred ancestral states of reproductive mode in the BayesTraits software (Pagel et

314 allow the use of species with unknown character states. Results were visualized in the R package 315 diversitree. The rates of trait evolution of the two continuous traits studied, namely, SVL and 316 body mass, were inferred in BAMM, using logarithms of both measures. Phylogenies were also 317 pruned to match the available information for both tree terminals and traits. We tested the 
318 correlation between SVL and body mass using phylogenetic independent contrasts (PIC;

319 Felsenstein, 1985) as implemented in the R package ape. Prior distributions to these subtrees

320 were set according to setBAMMPriors function from the BAMMtools R package (Rabosky et al.

321 2014). Chains were sampled every 1,000 generations until 50,000 trees were collected. The

322 results were summarized and visualized in BAMMtools. 


\section{Results}

324

325

Mabuyinae was recovered as a monophyletic group $(\mathrm{BS}=76)$. The first split in this

326

subfamily isolated the genus Dasia from the remaining Mabuyinae and was inferred to have

327

occurred at $30 \mathrm{Ma}$, with an HPD interval ranging from 20 - $48 \mathrm{Ma}$ (Supplementary File 4). The

biogeographical model with the highest likelihood was the DEC+J $(\operatorname{lnL}:-94.34)$. Therefore, the

addition of the $\mathrm{J}$ parameter for founder events significantly increased the likelihood of the DEC

330

model ( $p=1.2 \mathrm{e}^{-9}$, Table 3). Our results supported a model in which the genera Lankascincus and

Ristella split from Mabuyinae $(\mathrm{BS}=20)$ in the Oriental region.

After dispersal from the Oriental region to Africa, the ancestor of the CAM clade split

from Saharo-Arabian Trachylepis approximately $25 \mathrm{Ma}( \pm 16-41 \mathrm{Ma})(\mathrm{BS}=60)$. Subsequently,

334 the stock that gave rise to New World Mabuyinae dispersed from the Saharo-Arabian region to

335 the Neotropical Brazilian Subregion (Figure 1). The New World Mabuyinae were recovered as

336 monophyletic (BS=97), and the age of their LCA was estimated as $19 \mathrm{Ma}(12-31 \mathrm{Ma})$. Our

337 results supported the hypothesis that this lineage reached the Neotropics via the Brazilian

338 Subregion. From this region, the ancestor of Spondylurus and Copeoglossum dispersed to islands

339 of the West Indies. The continental clade later dispersed along the Brazilian Subregion.

340 Additional dispersal events to the West Indies were inferred to have occurred at least twice: in

341 the ancestor of Mabuya and in that of Alinea and Marisora. Marisora was not recovered as

342 monophyletic, with the Central American clade as sister to Alinea and the South American clade

343 as sister to Aspronema.

344 The origin of Trachylepis atlantica consisted of a different history. Firstly, the

345 monophyly of genus Trachylepis was not recovered. This genus was split into two lineages: one 
346 sister lineage of the CAM clade and another major clade to which T. atlantica belongs. Our

347 analysis supported the phylogenetic position of $T$. atlantica as a sister lineage of the clade

348 including the Europa Island T. infralineata, the Madagascan T. comorensis, and the continental

349 African T. maculilabris (BS =29). We found that the T. atlantica ancestor diverged from the

350 remaining Trachylepis in the Miocene, approximately $17 \mathrm{Ma}$ (between 10 and $27 \mathrm{Ma}$ ) in tropical

351 Africa. The younger diversification of $T$. atlantica indicates that the crossing of this species to

352 Fernando de Noronha occurred more recently than did the occupation of South America by the

353 CAM clade. Our analyses also suggested that once the ancestors of this major Trachylepis clade

354 reached Africa, dispersal events from the African continent occurred to Madagascar and nearby

355 islands at least three times, in addition to the dispersal to the Neotropics (T. atlantica). Our

356 results showed that a monophyletic Madagascan Trachylepis $(\mathrm{BS}=94)$ diverged from its sister

357 group approximately $19 \mathrm{Ma}(12-32 \mathrm{Ma})(\mathrm{BS}=23)$.

The ANOVA was used to test whether the full four-parameter GeoSSE model of the $N W /$

$359 \overline{N W}$ comparison (model 1) was statistically favored over simpler alternative models (models 2-

360

4). When we constrained speciation rates to be equal (model 2) and to present equal speciation

361 and extinction rates (model 4), the full model was supported over these alternative models ( $p=$

3620.00782 and $p=0.02900$, respectively). The comparison with the model that constrained

363 extinction rates (model $=3)$, however, was not significantly different $(p=0.15575)$.

GeoSSE analysis of the difference between the posterior distributions of speciation rates

365 in $N W / \overline{N W}$ lineages indicated a positive credible interval (CI) $(0.005-0.113)$, suggesting that

366 the speciation rates of South American clades $(\mathrm{NW})$ were indeed higher than those of the

367 remaining lineages $(\overline{N W})$. In BAMM, however, we failed to find a significant difference

368 between the posterior distributions of speciation rates (CI: $-0.030-0.031)$. We also found no 
369 evidence for diversification shifts during mabuyine diversification. However, the

370 macroevolutionary cohort matrix suggested heterogeneous macroevolutionary rate regimes in the

371 South American Mabuyinae and the remaining clades (Figure 2a). In both GeoSSE and BAMM

372 analyses, we failed to find differences between the extinction rates $\left(\mathrm{CI}_{\text {geosSE: }}-0.036-0.074\right.$,

$\left.373 \mathrm{CI}_{\text {BAMM }}:-0.027-0.027\right)$ and between the net diversification rates $\left(\mathrm{CI}_{\text {geosSE: }}:-0.010-0.090\right.$,

$\left.374 \mathrm{CI}_{\text {BAMм }}:-0.027-0.027\right)$ (Figure 2b).

375 Concerning the influence of viviparity on diversification rates, no submodels were

376 supported over the unconstrained model $(p>0.05)$. STRAPP analysis failed to find any

377 correlation between diversification rates and mode of reproduction $(p>0.05)$. We also found no

378 differences between the means obtained from the MCMC of the BiSSE (CI: $-0.018-0.125$, -

$3790.038-0.055,-0.051-0.049$, respectively for speciation, extinction, and transition rates).

380 The ancestor of CAM and their Trachylepis sister clade was recovered as viviparous by

381 BayesTraits $\left(\mathrm{P}_{\mathrm{BTML}}=0.751 ; \mathrm{P}_{\mathrm{BTBA}}=0.787\right)$ and as oviparous by BiSSE $\left(\mathrm{P}_{\mathrm{BiSSE}}=1\right)$, while the

382 ancestor of CAM alone was recovered as viviparous by all approaches $\left(\mathrm{P}_{\mathrm{BiSSE}}=0.953\right.$;

$383 \mathrm{P}_{\mathrm{BTML}}=0.992 ; \mathrm{P}_{\mathrm{BTBA}}=0.983$ ), suggesting that the ancestral species that colonised South America

384 was likely viviparous (Figure 2a). The ancestor of the subfamily Mabuyinae was inferred as

385 oviparous $\left(\mathrm{P}_{\mathrm{BiSSE}}=1 ; \mathrm{P}_{\mathrm{BTML}}=0.983 ; \mathrm{P}_{\mathrm{BTBA}}=0.980\right)$. Viviparity seems to have emerged several

386 times in the genus Trachylepis, as well as in the ancestor of Chioninia $\left(\mathrm{P}_{\mathrm{BiSSE}}=0.952\right.$;

$\left.387 \quad \mathrm{P}_{\mathrm{BTML}}=0.984 ; \mathrm{P}_{\mathrm{BTBA}}=0.971\right)$.

388 According to PIC results, SVL measurement and body mass were correlated $\left(p_{\text {LRP }}<\right.$

389 0.01), however, we had found differences in their evolutionary rates. The mean rates of trait

390 evolution of SVL and body mass were smaller in the New World clade than in the $\overline{N W}$ lineages.

391 However, these differences were not significant. In BAMM, we found an increase in the rate of 
392 SVL trait evolution in genus Chioninia. Only one clade presented an increase in the rate of body

393 mass trait evolution: the Seychelles Trachylepis (T. wrightii and T. brevicollis). STRAPP

394 analysis failed to find a significant correlation between the rate of species diversification and the

395 rate of SVL or body mass trait evolution $(p>0.05)$. 
396 Discussion

397

398

Our analyses based on a fossil-calibrated timetree support the hypothesis that the

399

occupation of South America by the ancestors of the Continental America Mabuyinae (CAM)

400

clade occurred between the Eocene and the Oligocene from the Saharo-Arabian region,

401

corroborating recent estimates (e.g. Pinto-Sánchez et al. 2015; Karin et al., 2016). This

402

colonization occurred independently of that of Trachylepis atlantica, which split from its tropical

403

African sister clade between the Oligocene and the Miocene. Therefore, our results corroborate

404

the hypothesis that the ancestor of T. atlantica dispersed from tropical Africa as suggested by

405

Mausfeld et al. (2002). The divergence between T. atlantica and its African ancestors was older

406

than the estimated age of the formation of the Fernando de Noronha archipelago (12.3-1.7 Ma;

407

Almeida, 2002). Thus, it is unlikely that the ancestors of T. atlantica reached South America in a

408

single transoceanic dispersal event. It is more probable to hypothesize a complex dispersal

409

scenario, with a series of dispersals through a transatlantic island corridor leading to Fernando de

410 Noronha, consistent with the Atlantogea model (Oliveira et al. 2009; Ezcurra and Agnolin,

411 2012). This stepping-stone mode of dispersal could explain the discrepancy between the ages of

412 genetic divergence and the formation of the archipelago because it would dissociate the

413 geological formation of the Fernando de Noronha archipelago from the genetic isolation of the

414 ancestor of $T$. atlantica. This result must be interpreted cautiously because choosing between

415 alternative biogeographical scenarios is influenced by the inferred timescale. The lack of extant

416 and extinct mabuyine species may have impacted divergence time estimates.

417 The age of the crown node of living CAM species was inferred to be much older than the

418 estimates reported by Carranza and Arnold (2003), 7-9 Ma. The credibility interval of our 
419 estimate (12-31 Ma), however, contains the ages inferred by Miralles and Carranza (2010),

420 Hedges and Conn (2012) and Karin et al. (2016), which dated this node at approximately 14 Ma.

421 Our results were still inconclusive to establish the precise sequence of events that gave rise to the

422 current geographical distribution of both CAM and T. atlantica. Nevertheless, the evolution of

423 these two American lineages of Mabuyinae corroborates a faunal connection between Africa and

424 the Neotropics, and suggests that dispersals may have occurred through island hopping, which is

425 more likely than a single sweepstake event across the Atlantic Ocean. In this sense, it is

426 interesting to mention that a species has been described in the mid-Atlantic Ascension Island by

427 Gray in 1838, which was subsequently assigned to genus Mabuya; however, no recent systematic

428 re-evaluation of this specimen is available (Mausfeld and Vrcibradic, 2002).

429 The arrival of Mabuyinae to South America seems to have changed the diversification

430 rate regime of this lineage. The evolutionary rates of both body mass and SVL traits were not

431 significantly altered after the arrival of the ancestors of New World clades, but the increases in

432 rates of both traits were found in island groups, such in Cape Verde's Chioninia and Seychelles'

433 Trachylepis. The viviparous CAM clade presents peculiar reproductive traits, such as a

434 specialized chorioallantoic placenta that provides fetal nutrition, similarly to eutherian mammals

435 (Vrcibradic and Rocha, 2011). This character was suggested to be synapomorphous by Mausfeld

436 et al. (2002). According to our analysis, the CAM ancestor was already viviparous, in agreement

437 with the large-scale analysis of Squamates (Pyron and Burbrink, 2013). However, Pyron and

438 Burbrink (2013) suggested an early origin of viviparity in Mabuyinae and multiple transitions to

439 oviparity, including the clade consisting of Chioninia and CAM + Heremites. On the other hand,

440 possibly because of topological differences, we estimated that the ancestor of Mabuyinae was

441 oviparous and multiple reversions to viviparity occurred later along the evolution of the lineage. 
443 the primitive characteristics of Asian Mabuyinae, suggested that the ancestors of this subfamily

444 first dispersed from Asia. Other works reasserted this hypothesis, although no formal statistical

445 analyses were conducted (Honda et al., 1999; 2003; Karin et al., 2016). Our results suggest that

446 the early members of Mabuyinae dispersed to Africa and then reached South America and

447 several oceanic islands. The inferred time-dated phylogeny and biogeographic reconstruction

448 similarly suggest an Oriental ancestral distribution, as corroborated by the distribution of the

449 genera Lankascincus and Ristella, which were recovered as sister clades of Mabuyinae and are

450 geographically distributed in the Oriental region (Sri Lanka and the Indian, respectively). Karin

451 et al., 2016 inferred that Eutropis, instead of Dasia, was the first Mabuyinae offshoot.

452 Nevertheless, as both genera are distributed in the Oriental region, this topological rearrangement 453 would not significantly alter the ancestral area reconstruction.

454 Finally, this study provides an updated timescale and estimates of macroevolutionary 455 regimes of the diversification of the subfamily Mabuyinae. Our focus was the occupation of the 456 South American continent by the subfamily Mabuyinae through an Oligocene/Eocene 457 transoceanic connection (Atlantogea), which could be responsible for approximately $29 \%$ of the 458 South American mammal diversity, suggesting the importance of this event to the extant 459 vertebrate diversity in South America (Marshall et al., 1982). CAM and T. atlantica are the only 460 representatives of the family Scincidae in South America accounting for $4 \%$ of the 461 approximately 1,560 squamate species on this continent (Uetz, 2000). Although there are species 462 of other subfamilies of Scincidae in Central America, these species seem to have never crossed 463 the Isthmus of Panama. The converse also seems correct because the only mabuyine genus 464 (Marisora) that partially occupied Central America based on our results had arrived via an 
465 intermediate dispersion through the West Indies. If this is the case, no representative of Scincidae

466 would be found in present day South American fauna in the absence of this Atlantogea

467 connection. Our results give an overall picture of the timing, biogeography and

468 macroevolutionary dynamics associated with the arrivals of the ancestors of this exceptional case 469 of transoceanic dispersal in two closely related lineages.

470

471 Acknowledgements

472

473 This study is part of the Doctoral Thesis of AGP from the Genetics Graduation Program 474 at the Federal University of Rio de Janeiro. 


\section{References}

476

477 Aberer AJ, Krompass D, Stamatakis A. 2013. Pruning Rogue Taxa Improves Phylogenetic

478 Accuracy: An Efficient Algorithm and Webservice. Systematic Biology 62:162-166.

479 Albert EM, San Mauro D, García-París M, Rüber L, Zardoya R. 2009. Effect of taxon sampling 480 on recovering the phylogeny of squamate reptiles based on complete mitochondrial genome 481 and nuclear gene sequence data. Gene 441:12-21.

482 Almeida FFM. 2002. Arquipélago de Fernando de Noronha. Sitios geologicos e paleontologicos 483 do Brasil 66:361-368.

484 Barker FK, Burns KJ, Klicka J, Lanyon SM, Lovette IJ. 2015. New insights into New World 485 biogeography, An integrated view from the phylogeny of blackbirds, cardinals, sparrows, 486 tanagers, warblers, and allies. The Auk 132:333-348.

487 Benton MJ, Donoghue P, Asher RJ. 2015. Constraints on the timescale of animal evolutionary 488 history. Palaeontologia Electronica 18.1.1FC:1-106.

489 Böhme M. 2010. Ectothermic vertebrates (Actinopterygii, Allocaudata, Urodela, Anura, 490 Crocodylia, Squamata) from the Miocene of Sandelzhausen (Germany, Bavaria). and their $84: 3-41$.

Böttcher R., Heizmann EPJ, Rasser MW, Ziegler R. 2009. Biostratigraphy and palaeoecology of a Middle Miocene (Karpathian, MN 5) fauna from the northern margin of the North Alpine Foreland Basin (Oggenhausen 2, SW' Germany). Neues Jahrbuch für Geologie und Paläontologie - Abhandlungen 254:237-260.

497 Briggs JC. 2003. Fishes and Birds, Gondwana Life Rafts Reconsidered. Systematic Biology 
$52: 548-553$.

499 Carranza S, Arnold EN. 2003. Investigating the origin of transoceanic distributions, mtDNA

500 shows Mabuya lizards (Reptilia, Scincidae) crossed the Atlantic twice. Systematics and

501 Biodiversity 1:275-282.

502 Castresana J. 2000. Selection of Conserved Blocks from Multiple Alignments for Their Use in

$503 \quad$ Phylogenetic Analysis. Molecular Biology and Evolution 17:540-552.

504 Das I. 2010. A Field Guide To The Reptiles Of South-East Asia, London: New Holland

505 Publishers.

506 de Oliveira FB, Molina EC, Marroig G. 2009. Paleogeography of the South Atlantic, a Route for

507 Primates and Rodents into the New World? In Garber PA, Estrada A, Bicca-Marques JC,

508 Heymann EW, Strier KB, ed. South American Primates, Developments in Primatology:

509 Progress and Prospects. New York: Springer. p 55-68.

510 de Queiroz A. 2005. The resurrection of oceanic dispersal in historical biogeography. Trends in

$511 \quad$ Ecology and Evolution 20:68-73.

512 de Queiroz A. 2014. The Monkey's Voyage, How Improbable Journeys Shaped the History of

$513 \quad$ Life. New York: Basic Books.

514 Edgar RC. 2004. MUSCLE, multiple sequence alignment with high accuracy and high

$515 \quad$ throughput. Nucleic Acids Research 32:1792-1797.

516 Estes R. 1983. Encyclopedia of Paleoherpetology. Stuttgart: Gustav Fischer Verlag.

517 Ezcurra MD, Agnolin FL. 2012. A New Global Palaeobiogeographical Model for the Late

518 Mesozoic and Early Tertiary. Systematic Biology 61:553-566.

519 FitzJohn RG. 2012. Diversitree, comparative phylogenetic analyses of diversification in R.

520 Methods in Ecology and Evolution 3:1084-1092. 
521 Goldberg EE, Lancaster LT, Ree RH. 2011. Phylogenetic Inference of Reciprocal Effects

522 between Geographic Range Evolution and Diversification. Systematic Biology 60:451-465.

523 Gouy M, Guindon S, Gascuel O. 2010. SeaView Version 4, A Multiplatform Graphical User

524 Interface for Sequence Alignment and Phylogenetic Tree Building. Molecular Biology and $525 \quad$ Evolution 27:221-224.

526 Greer AE. 1970. A subfamilial classification of scincid lizards. Bull. Mus. comp. Zool. Harvard $527 \quad 139: 151-183$.

528 Heads M. 2011. Old Taxa on Young Islands, A Critique of the Use of Island Age to Date Island529 Endemic Clades and Calibrate Phylogenies. Systematic Biology 60:204-218.

530 Hedges SB, Conn CE. 2012. A new skink fauna from Caribbean islands (Squamata, Mabuyidae, 531 Mabuyinae). Zootaxa 3288:1-244.

532 Heibl C. 2015. Phyloch. Available at http://www.christophheibl.de/Rpackages.html.

533 Holman JA. 1966. A small Miocene herpetofauna from Texas. Quarterly Journal of the Florida $534 \quad$ Academy of Sciences 29:267-275.

535 Holman JA. 1981. A herpetofauna from an early extension of the Harrison Formation (early 536 Miocene, Arikareean), Cherry County, Nebraska. Journal of Vertebrate Paleontology 1:4953756.

538 Honda M, Ota H, Kobayashi M, Nabhitabhata J, Yong H, and Hikida T. 1999. Evolution of 539 Asian and African Lygosomine Skinks of the Mabuya Group (Reptilia, Scincidae), A $540 \quad$ Molecular Perspective. Zoological Science 16:979-984.

541 Honda M, Ota H, Kohler G, Ineich I, Chirio L, Chen S-L, Hikida T. 2003. Phylogeny of the 542 Lizard Subfamily Lygosominae (Reptilia, Scincidae), with Special Reference to the Origin 543 of the New World Taxa. Genes Genet. Syst. 78:17-80. 
544 Joeckel RM. 1988. A new late Miocene herpetofauna from Franklin County, Nebraska. Copeia $545 \quad 3: 787-789$.

546 Karin BR, Metallinou M, Weinell JL, Jackman TR, Bauer AM. 2016. Resolving the higher-order 547 phylogenetic relationships of the circumtropical Mabuya group (Squamata: Scincidae): An 548 out-of-Asia diversification. Molecular Phylogenetics and Evolution 102:220-232.

549 Katoh K, Standley DM. 2013. MAFFT Multiple Sequence Alignment Software Version 7, 550 Improvements in Performance and Usability. Molecular Biology and Evolution 30:772-780.

551 Lanfear R, Calcott B, Ho SYW, Guindon S. 2012. PartitionFinder, Combined Selection of 552 Partitioning Schemes and Substitution Models for Phylogenetic Analyses. Molecular 553 Biology and Evolution 29:1695-1701.

554 Le M, Raxworthy CJ, Mccord WP, Mertz L. 2006. A molecular phylogeny of tortoises 555 (Testudines, Testudinidae). based on mitochondrial and nuclear genes. Molecular 556 Phylogenetics and Molecular Phylogenetics and Evolution 40:517-531.

557 Leigh EG, O'Dea A, Vermeij GJ. 2013. Historical biogeography of the Isthmus of Panama. 558 Biological Reviews 89:148-172.

559 Leite RN, Kolokotronis S-O, Almeida FC, Werneck FP, Rogers DS, Weksler M. 2014. In the 560 Wake of Invasion, Tracing the Historical Biogeography of the South American Cricetid $561 \quad$ Radiation (Rodentia, Sigmodontinae). PLoS ONE 9:e100687.

562 Lima A, Harris DJ, Rocha S, Miralles A, Glaw F, Vences M. 2013. Phylogenetic relationships of 563 Trachylepis skink species from Madagascar and the Seychelles (Squamata, Scincidae). $564 \quad$ Molecular Phylogenetics and Evolution 67:615-620.

565 Linder HP, Hardy CR, Rutschmann F. 2005. Taxon sampling effects in molecular clock dating, 566 An example from the African Restionaceae. Molecular Phylogenetics and Evolution 35:569- 
$567 \quad 582$.

568 Lomolino MV. 2010. Biogeography. Sunderland: Sinauer Associates.

569 Loss-Oliveira L, Aguiar B, Schrago CG. 2012. Testing Synchrony in Historical Biogeography:

570 The Case of New World Primates and Hystricognathi Rodents. Evolutionary Bioinformatics

$571 \quad 8: 127-137$.

572 Marshall LG, Webb SD, Sepkoski Jr JJ, Raup DM. 1982. Mammalian evolution and the Great

573 American Interchange. Science 215:1351-1357.

574 Matzke NJ. 2013. Probabilistic historical biogeography, new models for founder-event

575 speciation, imperfect, d. etection., and fossils allow improved accuracy and model-testing.

$576 \quad$ Frontiers of Biogeography 5:242-248.

577 Matzke NJ. 2014. Model Selection in Historical Biogeography Reveals that Founder-Event

578 Speciation Is a Crucial Process in Island Clades. Systematic Biology 63: 951-970.

579 Mausfeld P. 2000. First Data on the Molecular Phylogeography of Scincid Lizards of the Genus

580 Mabuya. Molecular Phylogenetics and Evolution 17:11-14.

581 Mausfeld P, Vrcibradic D. 2002. On the Nomenclature of the Skink (Mabuya). Endemic to the

582 Western Atlantic Archipelago of Fernando de Noronha, Brazil. Journal of Herpetology

$583 \quad 36: 292-295$.

584 Mausfeld P, Schmitz A, Bohme W, Misof B, Vrcibradic D, Rocha CFD. 2002. Phylogenetic

585 Affinities of Mabuya atlantica Schmidt, 1945, Endemic to the Atlantic Ocean Archipelago

586 of Fernando de Noronha (Brazil), Necessity of Partitioning the Genus Mabuya Fitzinger,

5871826 (Scincidae, Lygosominae). Zoologischer Anzeiger 241:281-293.

588 Meiri S. 2010. Length-weight allometries in lizards. Journal of Zoology 281:218-226.

589 Meiri S, Bauer AM, Chirio L, Colli GR, Das I, Doan TM, Feldman A, Herrera F-C, Novosolov 
M, Pafilis P, Pincheira-Donoso D, Powney G, Torres-Carvajal O, Uetz P, Van Damme R.

591 2013. Are lizards feeling the heat? A tale of ecology and evolution under two temperatures. Global Ecology and Biogeography 22: 834-845.

593 Mello B, Schrago CG. 2012. Incorrect handling of calibration information in divergence time 594 inference, an example from volcanic islands. Ecology and Evolution 2:493-500.

595 Miralles A, Carranza S. 2010. Systematics and biogeography of the Neotropical genus Mabuya, 596 with special emphasis on the Amazonian skink Mabuya nigropunctata (Reptilia, Scincidae). Molecular Phylogenetics and Evolution 54:857-869.

Morrone JJ. 2014. Biogeographical regionalisation of the Neotropical region. Zootaxa 3782:1110.

Mulcahy DG, Noonan BP, Moss M, Townsend TM, Reeder TW, Sites Jr JW, Wiens JJ. 2012.

601

602

603 991.

Pagel M, Meade A, Barker D. 2004. Bayesian Estimation of Ancestral Character States on Estimating divergence dates and evaluating dating methods using phylogenomic and mitochondrial data in squamate reptiles. Molecular Phylogenetics and Evolution 65:974Phylogenies. Systematic Biology 53:673-684.

Pinto-Sanchez NR, Calderón-Espinosa ML, Miralles A, Crawford AJ, Ramírez-Pinilla MP. 2015. Molecular phylogenetics and biogeography of the Neotropical skink genus Mabuya Fitzinger (Squamata: Scincidae) with emphasis on Colombian populations. Molecular Phylogenetics and Evolution 93:188-211. 
613 Pyron RA. 2014. Biogeographic Analysis Reveals Ancient Continental Vicariance and Recent

614 Oceanic Dispersal in Amphibians. Systematic Biology 63:779-797.

615 Pyron RA, Burbrink FT. 2013. Early origin of viviparity and multiple reversions to oviparity in 616 squamate reptiles. Ecology Letters 17:13-21.

617 Pyron R, Burbrink FT, Wiens JJ. 2013. A phylogeny and revised classification of Squamata, 618 including 4161 species of lizards and snakes. BMC Evolutionary Biology 13:93.

619 Rabosky DL. 2014. Automatic detection of key innovations, rate, shifts, and diversity620 dependence on phylogenetic trees. PLOS ONE 9:e89543.

621 Rabosky DL, Grundler M, Anderson C, Title CP, Shi JJ, Brown JW, Huang H, Larson JG. 2014. 622 BAMMtools, an R package for the analysis of evolutionary dynamics on phylogenetic trees. $623 \quad$ Methods in Ecology and Evolution 5:701-707.

624 Renner SS. 2004. Plant dispersal across the tropical atlantic by wind and sea currents.

625 International Journal of Plant Science 165:S23-S33.

626 Rowe TB, Cifelli RL, Lehman TM, Weil A. 1992. The Campanian Terlingua local fauna, with a 627 summary of other vertebrates from the Aguja Formation. Journal of Vertebrate Paleontology $628 \quad 12: 472-493$.

629 Sanmartín I, van der Mark P, Ronquist F. 2008. Inferring dispersal, a Bayesian approach to 630 phylogeny-based island biogeography, with special reference to the Canary Islands. Journal 631 of Biogeography 35:428-449.

632 Schrago CG, Mello B, Soares AER. 2013. Combining fossil and molecular data to date the 633 diversification of New World Primates. Journal of Evolutionary Biology 26: 2438-2446.

634 Schrago CG, Menezes AN, Moreira MAM, Pissinatti A, Seuánez HN. 2012. Chronology of 635 Deep Nodes in the Neotropical Primate Phylogeny, Insights from Mitochondrial Genomes. 
637 Simpson GG. 1950. History of the Fauna of Latin America. American Scientist 38: 361-389.

638 Simpson GG. 1953. The Major Features of Evolution. Columbia University Press, New York.

639 Sindaco R, Metallinou M, Pupin F, Fasola M, Carranza S. 2012. Forgotten in the ocean,

640 systematics, biogeography and evolution of the Trachylepis skinks of the Socotra

641 Archipelago. Zoologica Scripta 41:346-362.

642 Soares A, Schrago CG. 2012. The Influence of Taxon Sampling and Tree Shape on Molecular

643 Dating, An Empirical Example from Mammalian Mitochondrial Genomes. Bioinformatics

$644 \quad$ and Biology Insights 6:129-143.

645 Stamatakis A. 2014. RAxML Version 8, A tool for Phylogenetic Analysis and Post-Analysis of $646 \quad$ Large Phylogenies. Bioinformatics 30:1312-1313.

647 Stamatakis A, Hoover P, Rougemont J. 2008. A Rapid Bootstrap Algorithm for the RAxML $648 \quad$ Web Servers. Systematic Biology 57:758-771.

649 Talavera G, Castresana J. 2007. Improvement of Phylogenies after Removing Divergent and 650 Ambiguously Aligned Blocks from Protein Sequence Alignments. Systematic Biology $651 \quad 56: 564-577$.

652 Teeling EC. 2005. A Molecular Phylogeny for Bats Illuminates Biogeography and the Fossil $653 \quad$ Record. Science 307:580-584.

654 Uetz P. 2000. How many Reptile Species? Herpetological Review 31: 13-15.

655 Uetz, P. 1996. The Reptile Database. Available at http://www.reptile-database.org (accessed 15 656 January 2017).

657 Venczel M, Hír J. 2013. Micro-computed tomography study of a three-dimensionally preserved 658 neurocranium of Albanerpeton (Lissamphibia, Albanerpetontidae) from the Pliocene of 
659 Hungary. Journal of Vertebrate Paleontology 33:568-587.

660 Vidal N, Azvolinsky A, Cruaud C, Hedges SB. 2008. Origin of tropical American burrowing 661 reptiles by transatlantic rafting. Biology Letters 4:115-118.

662 Vitt LJ., Caldwell MW. 2009. Herpetology: An Introductory Biology of Amphibians and 663 Reptiles. Burlington: Elsevier.

664 Voloch CM, Vilela JF, Loss-Oliveira L, Schrago CG. 2013. Phylogeny and chronology of the 665 major lineages of New World hystricognath rodents, insights on the biogeography of the 666 Eocene/Oligocene arrival of mammals in South America. BMC Research Notes 6:1-9.

667 Voorhies MR, Holman JA, Xiang-xu X. 1987. The Hottell Ranch rhino quarries (basal Ogallala; 668 medial Barstovian), Banner County, Nebraska; Part I; Geologic setting, faunal lists, lower 669 vertebrates. Contributions to Geology, University of Wyoming 25:55-69.

670 Vrcibradic D, Rocha CFD. 2011. An overview of female reproductive traits in South American 671 Mabuya (Squamata, Scincidae), with emphasis on brood size and its correlates. Journal of $672 \quad$ Natural History 45:813-825.

673 Whiting AS, Sites Jr JW, Pellegrino KCM, Rodrigues MT. 2006. Comparing alignment methods 674 for inferring the history of the new world lizard genus Mabuya (Squamata, Scincidae). $675 \quad$ Molecular Phylogenetics and Evolution 38:719-730.

676 Yang Z. 2007. PAML 4: Phylogenetic Analysis by Maximum Likelihood. Molecular Biology 677 and Evolution 24:1586-1591. 
Table $\mathbf{1}$ (on next page)

General information on the loci used in this study. 


\begin{tabular}{lccccccccc}
\hline & $12 S$ & $16 S$ & enol & cytb & cmos & gapdh & myh & gpr149 & Total \\
\hline Number of sequenced species & 214 & 194 & 70 & 153 & 146 & 47 & 51 & 73 & 218 \\
Alignment length & 366 & 464 & 192 & 1,033 & 894 & 380 & 133 & 669 & 4,131 \\
Frequency of sites with missing data & 0.12 & 0.20 & 0.74 & 0.38 & 0.40 & 0.81 & 0.81 & 0.72 & 0.47 \\
Frequency of indels & 0.02 & 0.03 & 0.01 & 0.16 & 0.22 & 0.04 & 0.01 & 0.01 & 0.10 \\
\hline
\end{tabular}

2 
Table 2 (on next page)

Model comparisons performed in 'diversitree'.

Constraints in the macroevolutionary models subjected to ANOVA for differences in the rates of speciation $(\lambda)$ and extinction ( $\mu$ ) between New World (NW) and Old World (NW) areas (GeoSSE) and between viviparous ( $\mathrm{V}$ ) and non-viviparous $(\nabla)$ lineages (BiSSE). 


\begin{tabular}{|llll|}
\hline Model & Approach & Constrains & Parameters \\
& GeoSSE & $\mathrm{NA}$ & $\lambda_{N W}, \lambda_{\overline{N W}}, \mu_{N W}, \mu_{\overline{N W}}$ \\
& BiSSE & $\mathrm{NA}$ & $\lambda_{V}, \lambda_{\bar{V}}, \mu_{V}, \mu_{\bar{V}}$ \\
& GeoSSE & $\lambda_{N W}=\lambda_{\overline{N W}}$ & $\lambda, \mu_{N W}, \mu_{\overline{N W}}$ \\
Equal speciation & BiSSE & $\lambda_{V}=\lambda_{\bar{V}}$ & $\lambda, \mu_{V}, \mu_{\bar{V}}$ \\
& GeoSSE & $\mu_{N W}=\mu_{\overline{N W}}$ & $\lambda_{N W}, \lambda_{\overline{N W}}, \mu$ \\
Equal extinction & BiSSE & $\mu_{V}=\mu_{\bar{V}}$ & $\lambda_{V}, \lambda_{\bar{V}}, \mu$ \\
& GeoSSE & $\lambda_{N W}=\lambda_{\overline{N W}}$ & $\lambda, \mu$ \\
& & $\mu_{N W}=\mu_{\overline{N W}}$ & \\
Equal diversification & & $\lambda_{V}=\lambda_{\bar{V}}$ & $\lambda, \mu$ \\
& BiSSE & $\mu_{V}=\mu_{\bar{V}}$ & \\
\hline
\end{tabular}

1 


\section{Table 3(on next page)}

Model comparisons performed in BioGeoBEARS

Likelihood-ratio tests between null models (DIVALIKE and DEC) and more sophisticated models with the addition of the founder-event speciation (+J) (DIVALIKE $+\mathrm{J}$ and DEC+J). (LnL) Likelihood value. (DF) Degrees of freedom for the chi-square test. 


\begin{tabular}{|llrrrr|}
\hline model & Null model & LnLalt & LnLnull & DF & pval \\
DEC $+\mathrm{J}$ & DEC & -94.34 & -112.8 & 1 & $1.20 \mathrm{E}-09$ \\
DIVALIKE $+\mathrm{J}$ & DIVALIKE & -95.65 & -119.2 & 1 & $6.70 \mathrm{E}-12$ \\
\hline
\end{tabular}

1 


\section{Figure 1}

Time-dated phylogeny of the Mabuyinae with ancestral area reconstruction

Maps depict putative dispersals and vicariant events that culminated in the occupation of South America by this group. Ancestral area reconstruction was based on the results from $\mathrm{DEC}+\mathrm{J}$ because this model produced a significantly higher log-likelihood score. The black regions in pie charts represent bootstrap supports. 

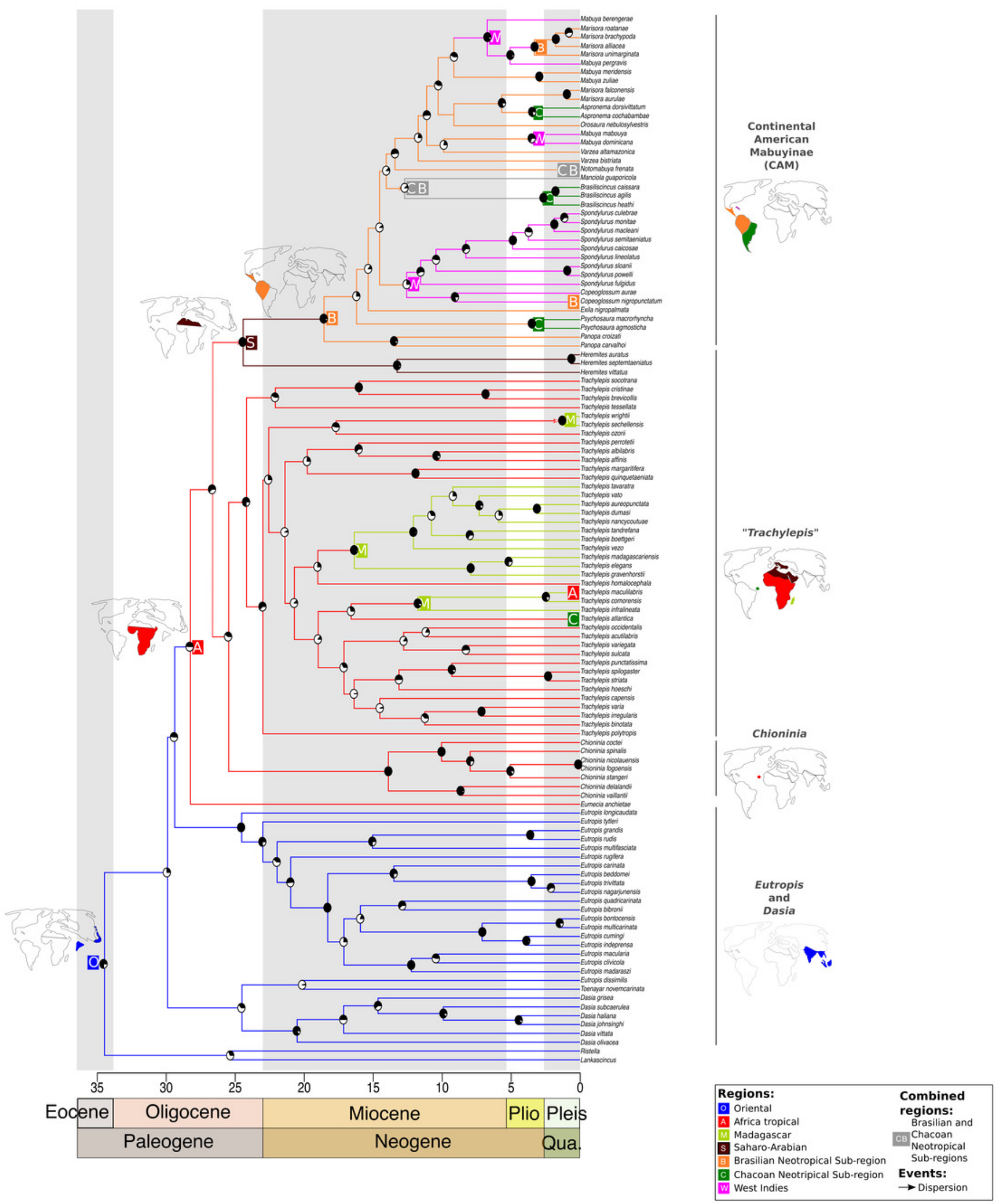


\section{Figure 2}

Macroevolutionary cohort matrix for the Mabuyinae subfamily.

A. Illustration of the macroevolutionary rates for the mabuyine lineage obtained using BAMM.

For reference, the BAMM tree was plotted at the upper margin of the figure. The pairwise probability that any two species share a common macroevolutionary rate dynamic was indicated by the color of each individual cell. Color scale is indicated th the right. The coral and brown circles in the upper tree represent the shifts found with BAMM in the traits SVL and body mass, respectively. In the left most tree topology, pie charts at nodes indicate the mode of reproduction inferred by BayesTraits, according to the probability of occurrence of each character. Red represents viviparity, and black represents oviparity. B. Marginal distributions of macroevolutionary rates inferred in BAMM and GeoSSE were also depicted for New World (green) and non-New World samples (orange).

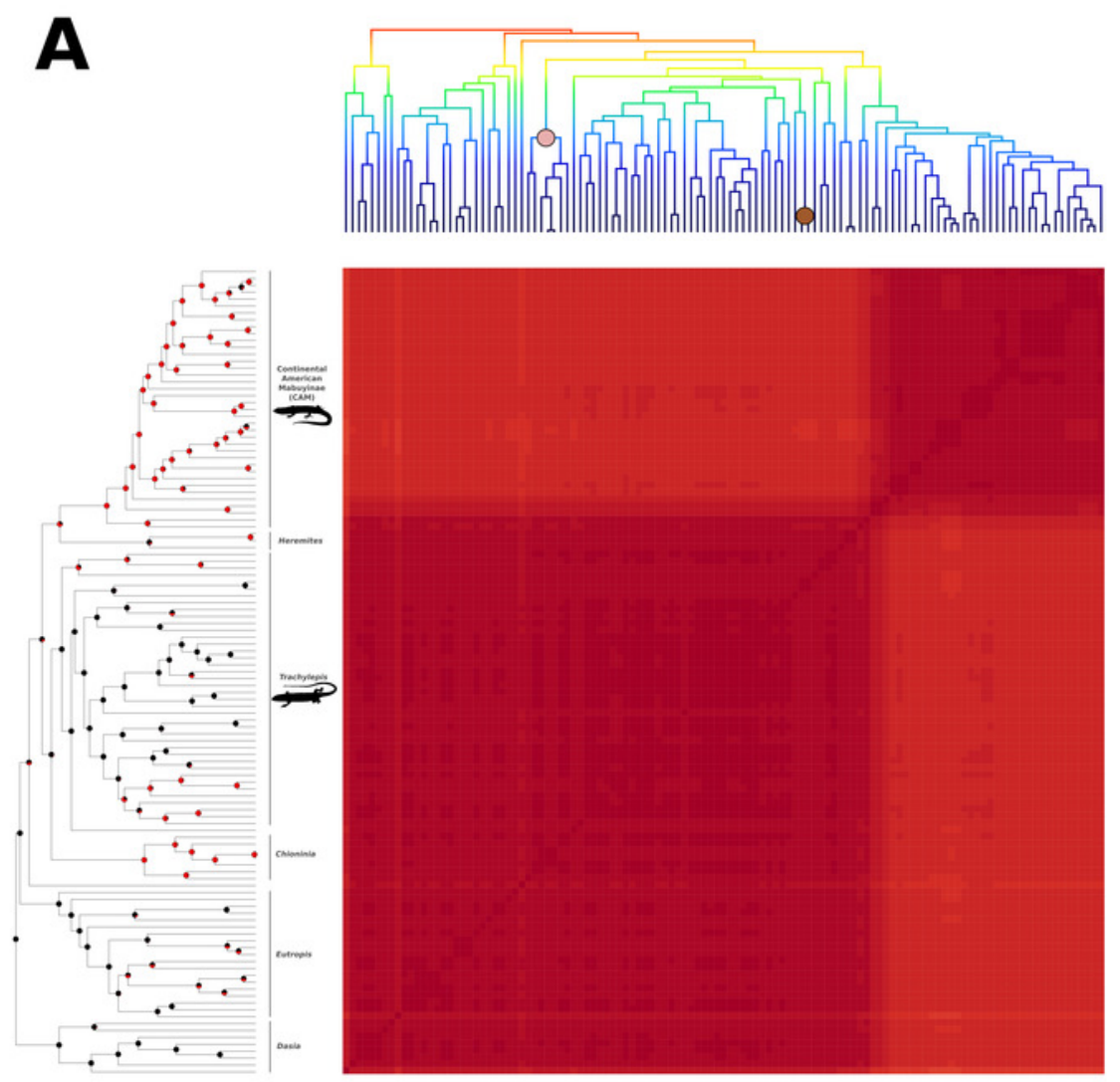

B

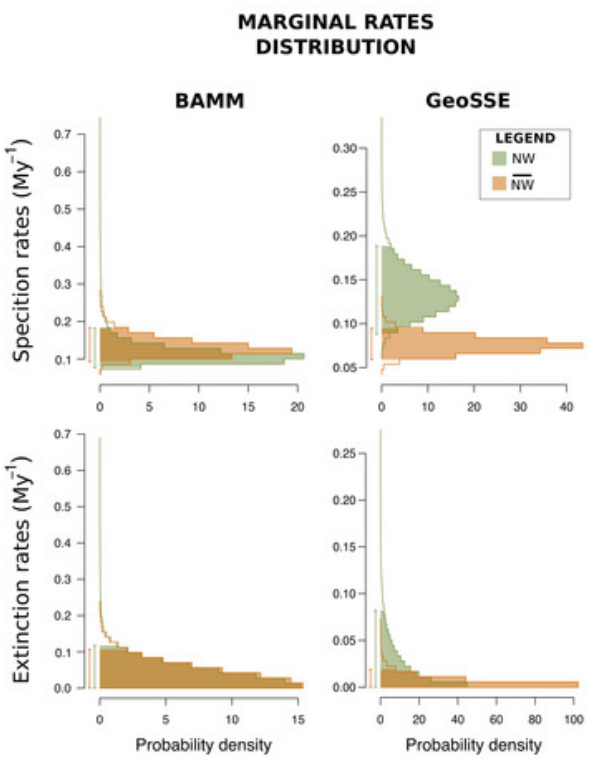

